\title{
The Subcellular Distribution of Acyltransferases which Catalyze the Synthesis of Phosphoglycerides
}

\author{
H. Erbl, E. F. Hill, and W. E. M. Lands \\ Department of Biological Chemistry, The University of Michigan, Ann Arbor
}

(Received January 16/March 18, 1969)

The distribution of acyltransferase activities in rat liver homogenates is described in relation to that for five other enzymes, each known to belong to a certain subcellular particle. Five different transfer reactions were studied with 1-acyl-sn-glycero-3-phosphorylcholine, 2-acyl-snglycero-3-phosphorylcholine, 1-acyl-sn-glycero-3-phosphorylethanolamine, 1-acyl-sn-glycero-3phosphate and $s n$-glycero-3-phosphate as substrates, and different acyl-CoA esters served as donors of acyl groups. Glucose-6-phosphatase and the acyltransferase activities studied were distributed with similar relative specific activities among the subfractions.

The results indicated that:

a) Acyltransferases were located in the microsomal membranes.

b) Nuclei and mitochondria did not have acyltransferase activity under the conditions used in these experiments, which were optimal for microsomal acyltransferases.

c) Plasma membranes appeared to have only a small amount of acyltransferase activity in comparison to that in the microsomal particles.

d) All acyltransferase activities tested showed similar patterns of distribution.

e) Acyltransferase activities may be useful in the future as marker enzymes for microsomal particles from tissues which do not contain glucose-6-phosphatase, but do contain the acyltransferase within the microsomal membranes.

Injection of $\left.{ }^{32} \mathrm{P}\right]$ phosphate into rats resulted in a rapid incorporation of radioactive phosphorus into liver phospholipids, especially into lecithin. Subfractionation of those livers showed the presence of labeled phospholipids in each subcellular fraction. Therefore, it was suggested that there may be substantial synthesis of phospholipids in both nuclei and mitochondrial fractions as well as in the endoplasmic reticulum [2]. However, Wilgram and Kennedy [3] demonstrated that cytidyldiphosphatecholine:glyceride cholinephosphotransferase is a microsomal enzyme. The only other known pathway for a de novo synthesis of lecithins is the methylation of phosphatidyl ethanolamines, a process that is also presumably located in the microsomal particles [4]. The data generally available on the de novo synthesis of

Unusual Abbreviations. DTNB, 5,5'-dithio-bis-(2-nitrobenzoate); the nomenclature of lipids follows CBN rules (see [1]).

Enzymes. Succinate dehydrogenase (EC 1.3.99.1); acid phosphatase (EC 3.1.3.2); glucose-6-phosphatase (EC 3.1. 3.9); 5'-rucleotidase (EC 3.1.3.5); uricase or urate: oxygen oxidoreductase (EC 1.7.3.3); acyl-CoA:sn-glycero-3-phosphate $O$-acyltransferase (EC 2.3.1.15); acyl-CoA:1-acyl-snglycero-3-phosphate $O$-acyltransferase; acyl-CoA:1-acyl-snglycero-3-phosphorylcholine $O$-acyltransferase; acyl-CoA:2acyl-sn-glycero-3-phosphorylcholine $O$-acyltransferase; acylCoA:1-acyl-sn-glycero-3-phosphorylethanolamine $O$-acyltransferase and acyl-CoA hydrolase (EC 3.1.2.2). lecithins failed to answer the question of how the various subcellular particles acquire their specific and non-random distribution pattern of fatty acids in the phospholipid molecules [5]. One approach to this problem comes from the finding in 1960 [6] of an acyl-sn-glycero-3-phosphorylcholine acylating system in the microsomal fraction of rat liver. Subsequently, many investigators reported acyl-CoA : acyl$s n$-glycero-3-phosphorylcholine acyltransferase activities in both microsomal and mitochondrial particles $[7-12]$. The phospholipase activities reported recently in these particles $[13-16]$ support the idea. of redistributing the fatty acid residues in phospholipids by means of a deacylating and reacylating cycle described ten years ago [17]. Additional studies with erythrocytes $[18,19]$ indicated that tissues could form lecithins from exogenous acyl-sn-glycero-3phosphorylcholine if no monoacyl precursor were available in the tissue due to the absence of phospholipase [18]. Munder et al. [20] also showed the action of acyltransferases during lecithin biosynthesis in erythrocyte membranes. Eventually, the experiments of Stein and Stein [21] with intact rats demonstrated. the action of acyltransferases in several tissues, including the liver, in vivo in the synthesis of lecithin and affirmed the availability of exogenous plasma acyl-sn-glycero-3-phosphorylcholine for lecithin syn- 
thesis indicated earlier [18]. In the present report we have studied the distribution of acyltransferase activities in subcellular fractions of rat liver to see if each membrane fraction has this synthetic ability.

\section{MATERIALS AND METHODS}

Coenzyme A thiolester derivatives (acyl-CoA) were prepared from the acid chlorides by a modification [22] of the method of Seubert [23]. 1-Acyl-sn-glycero-3. phosphorylcholine and 1-acyl--sn-glycero-3-phosphorylethanolamine were prepared by selective hydrolysis [10] of diacyl-sn-glycero-3-phosphorylcholine and diacyl-sn-glycero-3-phosphorylethanolamine. 2-Acyl-sn-glycero-3-phosphorylcholine was prepared from beef heart choline phosphoglycerides $(40 \%$ plasmalogen) as described by Lands [10]. In order to minimize acyl migration (from the 2- to 1-position), 2-acyl-sn-glycero-3-phosphorylcholine was freshly prepared prior to use and care was taken to maintain a pH of 6.5 to 7.5 in aqueous dispersions. rac-1-Acylsn-glycero-3-phosphate was prepared by phosphorylation of oleoylglycerol with $\mathrm{POCl}_{3}[24]$ and was isolated as the ethanol-insoluble sodium salt. The synthesis of 1(3)-sn- $\left[{ }^{14} \mathrm{C}\right]$ glycero-3-phosphate has been described in an earlier communication [25]. Stearoylpropanediol-1(3)-phosphorylcholine (1-stearoyl-2-deoxy-glycero-3-phosphorylcholine) was prepared by synthesis [26]. 5,5'-Dithio-bis-(2-nitrobenzoate) (D'TNB) was obtained from Aldrich Chemical Com. pany (Milwaukee, Wisconsin) and disodium- $\beta$-glycerophosphate, cytochrome $c$ (Type III, horse heart), glucose-6-phosphate, uric acid, AMP and succinic acid were purchased from Sigma Chemical Company (St. Louis, Missouri).

\section{Subfractionation of Homogenates}

Male Sprague Dawley rats (175 to $225 \mathrm{~g}$ ), which had been fasted for 24 hours, were sacrificed by decapitation, and the livers were perfused with icecold $0.9 \%$ sodium chloride in $1 \mathrm{mM}$ EDTA. Perfusion of rat livers with sodium chloride-EDTA was very effective in removing contaminating erythrocytes. The supernatant of these subfractionations was lightyellow colored in contrast to the red-colored supernatants of earlier experiments in which perfusion was omitted.

After weighing, the livers were homogenized in $0.25 \mathrm{M}$ sucrose containing $1 \mathrm{mM}$ EDTA, $\mathrm{pH} 7.3$ (hereafter called sucrose solution) using a Dounce ball-type homogenizer. The subsequent operations were performed at $1^{\circ}$ to $2^{\circ}$. In a typical experiment $3.18 \mathrm{~g}$ of rat liver were homogenized in $6 \mathrm{ml}$ of sucrose solution by 3 strokes with the loose pestle and 10 strokes with the tight pestle. During homogenization in sucrose solution, the pH dropped from 7.3 to 6.5 . The pH was readjusted to 7.3 with a solution of
$0.5 \%$ Tris before each centrifugation; otherwise, large quantitities of the microsomal particles sedimented in the lysosomal plus peroxisomal fraction.

The homogenate was centrifuged at $600 \times g$ for $5 \mathrm{~min}$, which means $3 \times 10^{3} \mathrm{~g}$ min as indicated in Fig.1. Supernatant $a$ was collected, and pellet $a$ was rehomogenized in $5 \mathrm{ml}$ of sucrose solution as described above. After centrifugation at $600 \times g$ for $5 \mathrm{~min}$, the procedure was repeated with $5 \mathrm{ml}$ of sucrose solution yielding pellet $b$ and then $c$. Supernatants $b$ and $c$ were combined with supernatant $a$. Pellet $c$ was rehomogenized in $4 \mathrm{ml}$ of sucrose solution and layered over $3 \mathrm{ml}$ of $0.6 \mathrm{M}$ sucrose solution.

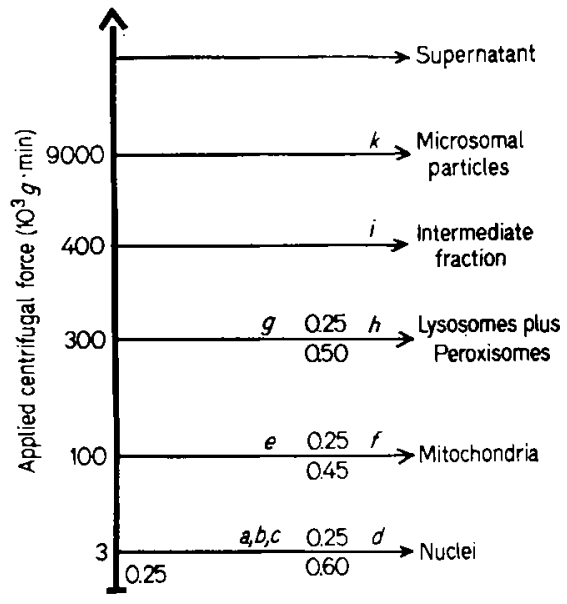

Fig. 1. Subfractionation of rat-liver homogenates. The ordinate shows the applied centrifugal forces in terms of $10^{3} \mathrm{~g} \cdot \mathrm{min}$ that produced the resulting subfractions. The sedimented pellets are indicated with the letters above the arrows. The values, $0.25,0.45,0.50$, and 0.60 indicate the molarity of sucrose in the solutions which were always $1 \mathrm{mM}$ in EDTA

Centrifugation at $600 \times g$ for 5 min resulted in pellet $d$, which was resuspended in $3.5 \mathrm{ml}$ of sucrose solution and was considered to be the nuclear fraction. Supernatant $d$ was combined with other supernatants and the total volume was adjusted to $28.0 \mathrm{ml}$ with sucrose solution. This fraction was called the cytoplasmic extract. Nuclei plus cytoplasmic extract are representative of the total homogenate, the total protein and the total activity.

$24.0 \mathrm{ml}$ of the cytoplasmic extract (corresponding to $2.72 \mathrm{~g}$ of the original fresh liver) wore centrifuged at $10000 \times g$ for $10 \mathrm{~min}$. Supernatant $e$ was collected, and pellet $e$ was rehomogenized in $4.0 \mathrm{ml}$ of sucrose solution and layered over $3.0 \mathrm{ml}$ of $0.45 \mathrm{M}$ sucrose solution. Centrifugation at $10000 \times g$ for $10 \mathrm{~min}$ resulted in pellet $f$ which was resuspended in $5.0 \mathrm{ml}$ of sucrose solution; it was designated as the mitochondrial fraction. Centrifugation of supernatant $e$ at $15000 \times g$ for $20 \mathrm{~min}$ yielded a loose pellet $g$, which was resuspended in supcrnatant $f$ and layered over 
$2.0 \mathrm{ml}$ of $0.5 \mathrm{M}$ sucrose solution. Centrifugation at $15000 \times g$ for $20 \mathrm{~min}$ yielded pellet $h$ which was resuspended in $2.5 \mathrm{ml}$ of sucrose solution and designated the lysosomal plus peroxisomal fraction.

The combined supernatants $g$ and $h$ were centrifuged at $20000 \times g$ for $20 \mathrm{~min}$. The small pellet $i$ was resuspended in $0.9 \mathrm{ml}$ of sucrose solution and called the intermediate fraction. Centrifugation of the supernatant $i$ at $100000 \times g$ for $90 \mathrm{~min}$ resulted in pellet $k$, which was resuspended in $4.0 \mathrm{ml}$ of sucrose solution and considered to be the microsomal fraction. Supernatant $k$ was the particle-free supernatant and was diluted to $40.0 \mathrm{ml}$. The fractions were kept at $0^{\circ}$ and analysed within 2 days. Loss of enzyme activity in this time period was not observed. Protein was estimated with the spectrophotometric assay of Warburg and Christian [27] and then determined according to Lowry et al. [28]. The protein concentration in the particulate fractions was about $20 \mathrm{mg} / \mathrm{ml}$ whereas that in the supernatant was approximately $5 \mathrm{mg} / \mathrm{ml}$.

The use of stepwise gradients in our fractionation procedure was very effective. Reports of 5 to $12 \%$ contamination of mitochondria with microsomal particles are not unusual $[\mathbf{1 6}, 29]$. The apparent contamination of microsomal particles in the mitochondrial fraction in this centrifugation procedure, however, was reduced to less than $4 \%$ of the total glucose-6-phosphatase activity in the homogenate.

\section{Enzyme Assays}

The enzyme activities were calculated from the initial reaction rates. Specific activities (nmoles of product/mg of protein/min) were always calculated during the time interval in which the increase of product was linear with time.

Succinate dehydrogenase activity was measured according to De Duve et al. [30] following the increase in absorbance at $550 \mathrm{~nm}$. The increase in molar absorbance by complete reduction of oxidized cytochrome $c$ is $1.96 \times 10^{4} \mathrm{M}^{-1} \times \mathrm{cm}^{-1}$ [31]. The incubation tubes contained oxidized cytochrome $c$ (50 nmole), protein $(0.2 \mathrm{mg})$ and sodium cyanide (200 nmole) in $0.9 \mathrm{ml}$ of $0.03 \mathrm{M}$ potassium phosphate buffer (pH 7.4). The reaction was initiated by adding $0.1 \mathrm{ml}$ of sodium succinate (30 $\mu$ mole) in phosphate buffer.

Acid phosphatase activity was determined as described by Wattiaux and De Duve [32] by analyzing the enzymatic hydrolysis of $\beta$-glycerophosphate at constant time intervals. EDTA was also included in the reaction mixture to inhibit alkaline phosphatase [33]. The incubation tubes contained protein $(1.2 \mathrm{mg})$ and Triton-X-100 (60 $\mu \mathrm{g})$ in $5.4 \mathrm{ml}$ of a buffer solution (pH6.1), 4.0 mM in EDTA and 7.3 mM in L-histidine. The reaction was initiated by adding $\beta$-glycerophosphate ( $200 \mu$ mole) in $0.6 \mathrm{ml}$ buffer solution. Aliquots of $1.5 \mathrm{ml}$ were taken after 5,25 and $35 \mathrm{~min}$, and the reaction was stopped by adding them to $0.15 \mathrm{ml}$ of $8 \%$ ice-cold trichloracetic acid. Free phosphate was determined according to Eibl and Lands [34]. The rate of phosphate hydrolysis was lincar in the reported time period.

Glucose-6-phosphatase activity was measured by analysing the hydrolysis of glucose-6-phosphate $[32,33]$. The incubation tubes contained protein $(1.2 \mathrm{mg})$, Triton-X-100 $(60 \mu \mathrm{g})$ in $5.4 \mathrm{ml}$ of buffer solution ( $\mathrm{pH} \mathrm{6.1)}, 4.0 \mathrm{mM}$ in EDTA, $1.0 \mathrm{mM}$ in potassium fluoride and $7.3 \mathrm{mM}$ in L-histidine. The reaction was initiated by adding glucose-6-phosphate $(100 \mu$ mole) in $0.6 \mathrm{ml}$ buffer. Aliquots of $1.5 \mathrm{ml}$ were taken after 5,15 , and $20 \mathrm{~min}$ and the reaction stopped by adding $0.15 \mathrm{ml}$ of cold $8 \%$ trichloracetic acid. Inorganic phosphate was determined as mentioned above. The increase of inorganic phosphate was linear in the reported time period.

$5^{\prime}$-Nucleotidase was measured according to $\mathrm{Em}$ melot et al. [35] by following the release of inorganic phosphate from AMP. The incubation mixture contained protein $(1.2 \mathrm{mg})$ and Triton-X-100 (60 $\mu \mathrm{g})$ in $5.4 \mathrm{ml}$ of buffer solution $(\mathrm{pH} 7.2), 100 \mathrm{mM}$ in potassium chloride, $5 \mathrm{mM}$ in magnesium chloride and $50 \mathrm{mM}$ in Tris. The reaction was initiated by adding AMP (10 umole) in $0.6 \mathrm{ml}$ buffer. Aliquots of $1.5 \mathrm{ml}$ were taken after exactly 5, 25, and $35 \mathrm{~min}$, and the reaction was stopped by adding $0.15 \mathrm{ml}$ of $8 \%$ icecold trichloracetic acid. Inorganic phosphate was determined as mentioned before. The increase of inorganic phosphate was linear in the reported time period. Under the conditions of this test, $\beta$-glycerophosphate was not a substrate, indicating that acid phosphatase does not influence the results obtained in this assay for $5^{\prime}$-nucleotidase.

Uricase activity was measured according to De Duve et al. [30] following the increase in absorbance at $293 \mathrm{~nm}$. The molar absorbance of uric acid is $1.26 \times 10^{4} \mathrm{M}^{-1} \times \mathrm{cm}^{-1}$. The incubation tubes contained protein $(0.2 \mathrm{mg})$ and 1 -acyl-sn-glycero-3phosphorylcholine $(85 \mathrm{nmole})$ in $0.9 \mathrm{ml}$ of $0.03 \mathrm{M}$ potassium phosphate buffer ( $\mathrm{pH}$ 7.4). The reaction was initiated by adding uric acid (60 nmole) in $0.1 \mathrm{ml}$ of buffer. Reaction rates were calculated from the linear decrease in absorbance in the first $2 \mathrm{~min}$. The rates were not changed in the presence of the detergent, 1-acyl-sn-glycero-3-phosphorylcholine, as shown in Fig. 2.

Acyl-CoA:sn-glycero-3-phosphate acyltransferase activity was measured by following the incorporation of $s n$-[14 C]glycero-3-phosphate into lipid. The incubation tubes contained $86 \mu$ moles of $s n$ - $\left[{ }^{14} \mathrm{C}\right] \mathrm{glycero}-$ 3 -phosphate ( 71000 counts $/ \mathrm{min})$, 5 nmoles-palmitoylCoA, $20 \mu$ moles 'Tris-Cl, pH 8.0 and $0.5 \mathrm{mg}$ of protein in a final volume of $0.30 \mathrm{ml}$. The reaction was initiated by the addition of protein. and the incubations were performed at room temperature for 1.5 and $3.0 \mathrm{~min}$. The short time periods were necessary to 
produce an essentially linear increase of product with time; longer periods of incubation gave a nonlinear increase of product with time. The reaction was terminated by the forceful addition of $6.0 \mathrm{ml}$ of chloroform-methanol (2:1). Then $0.36 \mathrm{mM} \mathrm{HCl}$ in $2 \%$ acetic acid $(1.2 \mathrm{ml})$ was added, and the resultant lower phase was washed twice with 0.3 volumes of chloroform-methanol- $0.36 \mathrm{mM} \mathrm{HCl}$ in $2 \%$ acetic acid $(3: 48: 47)$. The chloroform layer was then transferred to a scintillation vial, and the solvent was removed in a stream of $\mathrm{N}_{2}$. The samples were assayed for radioactivity in $10 \mathrm{ml}$ of dioxane scintillation

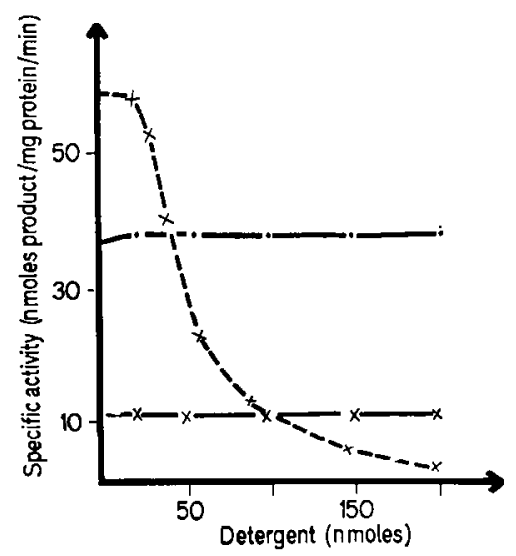

Fig. 2. The effect of detergent on enzyme activities. Incubations were done as described in Methods, using increasing amounts of detergent as indicated on the abscissa. Both 1-stearoyl-2deoxy-glycero-3-phosphorylcholine and 1-acyl-sn-glycero3-phosphorylcholine from egg yolk exhibited identical detergent effects on the enzymes studied and are not shown separately. The symbols indicate: $X----X$, succinate dehydrogenase (mitochondrial fraction); - - - - - , uricase (lysosomal plus peroxisomal fraction); $x-\ldots, x$, unspecific side reaction mainly due to acyl-CoA hydrolase using oleoyl$\mathrm{CoA}$ and linoleoyl-CoA (microsomal fraction). In this case, 1-acyl-sn-glycero-3-phosphorylcholine was, of course, omitted

fluid [36] in a Packard series 2000 scintillation spectrometer. Zero-time controls and controls in which acyl-CoA or protein was omitted were used to correct for the carry-over of $s n-\left[{ }^{14} \mathrm{C}\right]$ glycero-3-phosphate into the lipid extracts.

Acyl-CoA:Phospholipid acyltransferase activities were assayed by following the increase in absorbance at $412 \mathrm{~nm}$ produced by the reaction of released CoASH with DTNB. Each reaction vessel contained $1 \mu$ mole DTNB, Tris-Cl, $90 \mu$ moles $\mathrm{pH} \mathrm{7.4,} \mathrm{and}$ $0.20 \mathrm{mg}$ of protein in a total volume of $1.0 \mathrm{ml}$, and the reaction was initiated by the addition of acyl-CoA. When acyl-CoA:1-acyl-sn-glycero-3-phosphate acyltransferase activity was assayed, 56 nmoles 1-acyl$s n$-glycero-3-phosphate and 19 nmoles acyl-CoA were added to each reaction mixture. When acyl-CoA: acyl-sn-glycero-3-phosphorylcholine or 1-acyl-sn- glycero-3-phosphorylethanolamine acyltransferase activity was assayed, 170 nmoles acyl-sn-glycero-3phosphorylcholine or 400 nmoles 1-acyl-glycero-3phosphorylethanolamine and 30 nmoles acyl-CoA were included in the reaction mixture. Each activity was assayed with at least two different acyl-CoAs; except that acyl-CoA : 1-acyl-sn-glycero-3-phosphorylethanolamine acyltransferase was determined only with eicosatrienoyl-CoA.

In past studies with microsomal acyltransferases [37], the rate of acyltransfer to phospholipid was corrected for side reactions of acyl-CoA by measuring the release of mercaptan in the absence of acceptor phospholipid. Similar control experiments with nuclear, mitochondrial or lysosomal plus peroxisomal fractions were unsatisfactory, since the addition of the acyl-CoA to the reaction mixture resulted in a slow, extended decrease in absorbancy at $412 \mathrm{~nm}$. On the other hand, the addition of monoacyl phospholipid yielded a rapid decrease in absorbancy which was complete within 10 to 30 sec. To avoid turbidity effects, and to provide the enzyme with the same physicochemical environment, 1-stearoyl-2-deoxyglycero-3-phosphorylcholine was added to the incubation mixture when assaying the unspecific side reaction. 1-Stearoyl-2-deoxy-glycero-3-phosphorylcholine is not a substrate for the acyltransferases and does not influence the rate of the side reaction in the microsomal fraction, as shown in Fig.2, but is known to have detergent properties similar to the 1-acyl-sn-glycero-3-phosphorylcholine prepared from egg yolk $[38,39]$. Moreover, two other enzymes were tested for their sensitivity to 1-stearoyl2-deoxy-glycero-3-phosphorylcholine and 1-acyl-snglycero-3-phosphorylcholine. The rate of action of uricase is not influenced, but succinate dehydrogenase showed a rapid loss of activity with increasing amounts of detergent.

\section{RESULTS}

In the present study, we have fractionated rat liver homogenates by differential centrifugation (see Fig. 1) into six fractions: nuclei, mitochondria, lysosomes plus peroxisomes, an intermediate fraction, microsomal particles and a supernatant fraction. The designation of the fractions was arbitrary. The real composition of the particulate fractions and the success of the fractionation were indicated by the presence of marker enzymes which are well known to occur in certain particulate fractions [40]. Succinate dchydrogenase, acid phosphatase, uricase, glucose-6-phosphatase, and 5'-nucleotidase were chosen as marker enzymes $[40,41]$ for mitochondria, lysosomes, peroxisomes, microsomal particles and plasma membranes, respectively.

The total activities, percentage distribution of activity, and the percentage of total activity reco- 
Table 1. Distribution of enzyme activity and protein in subfraction of rat liver homogenates

Total activity and total protein are given in $\mu$ moles per min and $\mathrm{mg}$ respectively per $\mathrm{g}$ of fresh liver. The total amounts were calculated by addition of the values obtained for nuclei and cytoplasmic extract. $N$ stands for nuclei, $M$ for mitochondria, $\mathrm{L}$ for lysosomes plus peroxisomes, I for an intermediate fraction, $\mathrm{P}$ for microsomal particles and S for supernatant

\begin{tabular}{|c|c|c|c|c|c|c|c|c|c|}
\hline \multirow{2}{*}{ A. Marker enzymes } & \multirow{2}{*}{\multicolumn{2}{|c|}{ Total activity }} & \multicolumn{6}{|c|}{ Activity in fractions } & \multirow{2}{*}{ Recovery } \\
\hline & & & $\mathbf{N}$ & $\mathbf{M}$ & $\mathbf{L}$ & I & $\mathbf{P}$ & $\mathbf{s}$ & \\
\hline & \multicolumn{2}{|c|}{$\mu$ moles/min $\times g$} & \multicolumn{6}{|c|}{ Percentage of total } & $\%$ \\
\hline Succinate dehydrogenase & & 64.0 & 15.7 & 62.0 & 16.2 & 0.9 & 0.0 & 0.0 & 94.8 \\
\hline Acid phosphatase & & 2.3 & 0.0 & 19.5 & 35.1 & 5.6 & 8.8 & 19.7 & 88.7 \\
\hline Uricase & & 1.1 & 0.0 & 15.9 & 62.1 & 7.1 & 5.8 & 0.0 & 90.8 \\
\hline $5^{\prime}$-Nucleotidase & & 1.9 & 8.3 & 7.1 & 19.8 & 10.5 & 42.4 & 0.0 & 88.1 \\
\hline Glucose-6-phosphatase & & 5.4 & 3.2 & 3.5 & 15.3 & 9.6 & 58.4 & 0.0 & 90.0 \\
\hline \multicolumn{10}{|l|}{ B. Acyltransferases } \\
\hline 1-Acyl-sn-glycero-3-phosphorylcholine & $+20: 3$ & 2.8 & 2.1 & 1.8 & 14.4 & 9.6 & 61.4 & 0.0 & 89.3 \\
\hline 1-Acyl-sn-glycero-3-phosphorylcholine & $+18: 2$ & 2.2 & 2.1 & 1.8 & 13.5 & 10.2 & 59.9 & 0.0 & 87.5 \\
\hline 1-Acyl-sn-glycero-3-phosphorylcholine & $+18: 1$ & 2.2 & 2.1 & 1.8 & 13.5 & 9.6 & 58.4 & 0.0 & 85.4 \\
\hline 2-Acyl-sn-glycero-3-phosphorylcholine & $+16: 0$ & 1.8 & 0.0 & 0.0 & 12.6 & 9.3 & 61.4 & 0.0 & 83.3 \\
\hline 2-Acyl-sn-glycero-3-phosphorylcholine & $+18: 0$ & 0.8 & 0.0 & 0.0 & 14.4 & 8.7 & 55.5 & 0.0 & 78.6 \\
\hline 1-Acyl-sn-glycero-3-phosphorylethanolar & $e+20: 3$ & 0.6 & 1.1 & 0.0 & 14.4 & 9.9 & 62.8 & 0.0 & 88.2 \\
\hline 1-Acyl-sn-glycero-3-phosphate & $+18: 1^{\mathrm{a}}$ & 1.1 & 2.7 & 3.7 & 10.9 & 26.6 & 38.1 & 0.0 & 82.1 \\
\hline 1-Acyl-sn-glycero-3-phosphate & $+16: 0^{\mathrm{s}}$ & 0.8 & 1.5 & 4.9 & 7.0 & 32.1 & 32.0 & 0.0 & 77.5 \\
\hline sn-glycero-3-phosphate & $+16: 0^{a}$ & 0.1 & 4.1 & 6.9 & 13.1 & 11.0 & 25.3 & 1.7 & 62.0 \\
\hline Total protein (mg/g liver) & \multicolumn{2}{|c|}{204} & 10.5 & 17.7 & 9.0 & 3.1 & 14.6 & 39.4 & 94.3 \\
\hline
\end{tabular}

- The values represent the average of three experiments whereas all others are the average of six scparate fractionations.

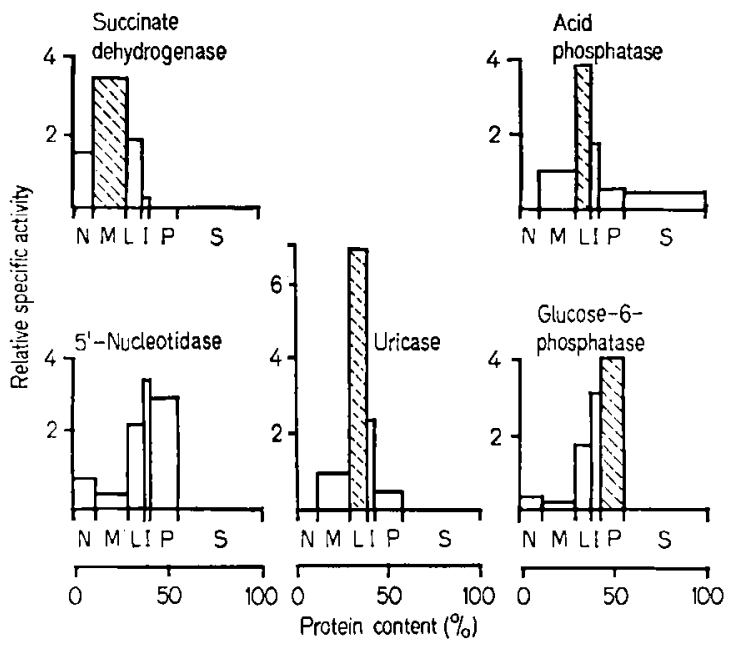

Fig.3. Distribution of marker enzymes. The ordinate shows the relative specific activity of the marker enzyme. The relative specific activity of an enzyme is defined as the percentage of the total activity in a fraction divided by the percentage of the total protein in that fraction. This corresponds to the value obtained by dividing the specific activity (nmole product/mg protein/min) of the fraction by the specific activity of the total homogenate. Thus, the relative specific activity of the homogenate is always 1.0. The percentage of protein is indicated on the abscissa. The fractions with shaded lines are the fractions with both the highest relative specific activities and the largest amount of total activity. $\mathbf{N}$ stands for nuclei, $M$ for mitochondria, L for lysosomes plus peroxisomes, I for an intermediate fraction, $\mathrm{P}$ for microsomal particles, and $\mathrm{S}$ for supernatant covered for marker enzymes together with the total protein and the recovered protein in the fractions are summarized in Table $1 \mathrm{~A}$. The results are average values obtained from 6 different subfractionations. The recovery of protein and of total activity in the fractions ranged between 88 and $95 \%$. The total activities corresponded with the values reported by other investigators $[40,41]$ when one considers the fact that our data were obtained at $20^{\circ}$.

Fig. 3 presents the distribution of marker enzymes among the subcellular fractions in a manner suggested by De Duve [40]. Succinate dehydrogenase had the highest relative specific activity ( 3.5 times the specific activity of the homogenate) in the mitochondrial fraction. Acid phosphatase and uricase had the highest relative specific activities (3.9 and 6.9, respectively) in the lysosomal plus peroxisomal fraction, while the highest relative specific activity (4.0) for glucose-6-phosphatase was in the microsomal particles. Moreover, the highest relative specific activity was found in the fraction with the largest amount of total activity for each enzyme with the exception of $5^{\prime}$-nucleotidase. $5^{\prime}$-Nucleotidase had the highest value of relative specific activity in the intermediate fraction; but the largest quantity of activity was found in the microsomal particles. Supernatant is not considered in the further discussion, because the activities in this fraction of the enzymes studied were zero with the exception of acid phosphatase. 
Table 2. Relative specific activities of glucose-6-phosphatase and various acyltransferases The relative specific activity of an enzyme is defined in Fig. 3

\begin{tabular}{|c|c|c|c|c|c|}
\hline \multirow{2}{*}{ Enzyme } & \multicolumn{5}{|c|}{ Fractions } \\
\hline & $\mathbf{N}$ & $\mathbf{M}$ & L & $\mathbf{I}$ & $\mathbf{P}$ \\
\hline Glucose-6-phosphatase & 0.3 & 0.2 & 1.7 & 3.1 & 4.0 \\
\hline $\begin{array}{l}\text { 20:3 CoA:1-acyl-sn-glycero-3-phosphorylcholine acyltransferase } \\
\text { 18:2 CoA:1-acyl-sn-glycero-3-phosphorylcholine acyltransferase } \\
\text { 18:1 CoA:1-acyl-sn-glycero-3-phosphorylcholine acyltransferase }\end{array}$ & $\begin{array}{l}0.2 \\
0.2 \\
0.2\end{array}$ & $\begin{array}{l}0.1 \\
0.1 \\
0.1\end{array}$ & $\begin{array}{l}1.6 \\
1.5 \\
1.5\end{array}$ & $\begin{array}{l}3.1 \\
3.3 \\
3.1\end{array}$ & $\begin{array}{l}4.2 \\
4.1 \\
4.0\end{array}$ \\
\hline $\begin{array}{l}\text { 16:0 CoA:2-acyl-sn-glycero-3-phosphorylcholine acyltransferase } \\
\text { 18:0 CoA:2-acyl-sn-glycero-3-phosphorylcholine acyltransferase }\end{array}$ & $\begin{array}{l}\mathbf{0} \\
\mathbf{0}\end{array}$ & $\begin{array}{l}0 \\
0\end{array}$ & $\begin{array}{l}1.4 \\
1.6\end{array}$ & $\begin{array}{l}3.0 \\
2.8\end{array}$ & $\begin{array}{l}4.2 \\
3.8\end{array}$ \\
\hline 20:3 CoA:1-acyl-sn-glycero-3-phosphorylethanolamine acyltransferase & 0.1 & 0 & 1.6 & 3.1 & 4.3 \\
\hline $\begin{array}{l}\text { 18:1 CoA:1-acyl-sn-glycero-3-phosphate acyltransferase } \\
\text { 16:0 CoA:1-acyl-sn-glycero-3-phosphate acyltransferase }\end{array}$ & $\begin{array}{l}0.2 \\
0.2\end{array}$ & $\begin{array}{l}0.2 \\
0.3\end{array}$ & $\begin{array}{l}1.1 \\
0.6\end{array}$ & $\begin{array}{l}3.0 \\
3.4\end{array}$ & $\begin{array}{l}3.4 \\
3.4\end{array}$ \\
\hline 16:0 CoA:sn-glycero-3-phosphate & 0.4 & 0.4 & 1.3 & 1.9 & 2.2 \\
\hline
\end{tabular}

Table 1 presents a direct comparison of the acyltransferase activities with the distribution pattern of the marker enzymes. Similar results were obtained with acyl-CoA : 1-acyl-sn-glycero-3-phosphorylcholine 2-acyl-sn-glycero-3-phosphorylcholine and 1-acyl$s n$-glycero-3-phosphorylethanolamine acyltransferases. Although the total activity was dependent upon the acyl-CoA used as substrate, the total recovery of activity was approximately $85 \%$ in each case. Acyl-CoA:1-acyl-sn-glycero-3-phosphate acyltransferase was measured with oleoyl- and palmitoyl-CoA. The total activity was about $1 \mu \mathrm{mole} / \mathrm{g}$ fresh liver/min and the overall recovery was approximately $80 \%$. Only small total activities of about $0.1 \mu \mathrm{mole} / \mathrm{g}$ fresh liver $/ \mathrm{min}$ with a recovery of $62 \%$ were found for the palmitoyl-CoA: $s n$-glycero-3-phosphate acyltransferase. The incomplete recovery of this activity makes it difficult to prove the absence of some acyl-CoA : $s n$-glycero-3-phosphate acyl-transferase in mitochondria, but the relative specific activities shown in Table 2 indicate a distribution similar to that for glucose-6-phosphatase.

Without exception, the acyltransferases studied showed the highest relative specific activity with a value of about 4.0 in the microsomal particles (see Table 2). The value for the relative specific activity of an enzyme represents a purification factor in relation to the total homogenate. Generally the values for the relative specific activities are far below 1.0 in the nuclei and mitochondria, about 1.5 in the lysosomal plus peroxisomal fraction and about 3 in the intermediate fraction. The close relationship between the distribution patterns of the acyltransferase and the glucose-6-phosphatase activities is obvious.

As mentioned before, the microsomal fraction contained the largest amount of glucose-6-phosphatase, linoleoyl-CoA:1-acyl-sn-glycero-3-phosphorylcholine acyltransferase and $5^{\prime}$-nucleotidase activity corresponding to 58,60 and $42 \%$, respectively. Based on the observations of Coleman et al. [41], a subfrac- tionation of microsomal membranes was performed. The three enzymes were analyzed in each step of the preparation, and the values for specific activity and relative specific activity are presented in Table 3. The specific activities for glucose-6-phosphatase and acyltransferase in the pellet were 128 and 49 , and they corresponded to a purification factor of 4.9 and 4.5, respectively. 5 -Nucleotidase, on the other hand, showed the highest specific activity in the material at the interface. The specific activity was 96 , which meant a 10.7-fold purification in relation to the homogenate. Glucose-6-phosphatase activity in all experiments was paralleled by corresponding amounts of acyltransferase activity.

\section{DISCUSSION}

The presence of acyltransferase activities has frequently been reported in mitochondria, in addition to the microsomal fraction of liver [6-12]. The primary aim of those reports was not to document the subcellular distribution of acyltransferases; nevertheless, a general acceptance of acyltransferase activity in mitochondria is implied in recent reports $[12,29,42]$. Our data with subfractions of rat liver, however, reveal that acyltransferase activity among the fractions parallels very closely that of glucose-6phosphatase. This was true whether one compared the relative specific activities of individual particulate fractions or the total recovery of activity for acyltransferase and glucose-6-phosphatase in individual subfractions.

The low values for relative specific activity of acyltransferases in the nuclear and mitochondrial fractions indicate that nuclei and mitochondria do not contain acyltransferase activity. Actually, more glucose-6-phosphatase activity occurred in the mitochondria than acyl-CoA:1-acyl-sn-glycero-3-phosphorylcholine acyltransferase or acyl-CoA:1-acyl$s n$-glycero-3-phosphorylethanolamine acyltransferase activities. With these acyltransferases the 
relative specific activity of the microsomal fractions was 20 to 40 times the relative specific activity observed in the nuclear and mitochondrial fractions. The small activities of acyltransferases observed in these fractions corresponded very closely to glucose6-phosphatase activity indicating that the low amounts of acyltransferase activity are due to contamination by microsomal particles rather than by synthetic activities of the nuclei or mitochondria.

Significant quantities (13 to $20 \%$ ) of acyltransferase activity occurred in the lysosomal plus peroxisomal fraction, and a 1 to 2 -fold increase in specific activity over the total homogenate was observed. Again the acyltransferase activity coincided with the glucose-6-phosphatase activity observed in this fraction. Moreover, the mitochondrial fraction contained considerable amounts of lysosomes and peroxisomes (15 to $20 \%$ ), but as indicated above, only minimal acyltransferase activity was observed in the mitochondrial fraction. Thus, our results strongly suggest that the acyltransferase activity of liver resides only in the endoplasmic reticulum.

In view of the high specific activity of acyltransferases (e.g. 1 to $3 \mu \mathrm{moles} / \mathrm{min} / \mathrm{g}$ of fresh liver), it is not surprising that some activity has frequently been measured in the mitochondrial fraction. This is especially true when one considers that such studies have utilized isotopes and periods of incubation ranging from 10 to $60 \mathrm{~min}$, and that apparently only minimal care was taken to avoid contamination of the mitochondria with microsomes. In our experience, the use of fasted animals, perfusion of the liver and the use of discontinuous gradients were all found to be helpful in minimizing contamination of mitocondria with microsomes.

In the present study, various acyl-CoAs were utilized for assay of acyltransferase activities. Recent studies of Reitz et al. [43] indicated that separate enzymes may be present in the endoplasmic reticulum for esterification of $\Delta^{9}$-octadecenoic acid and $\Delta^{12}$. octadecenoic acid to 1-acyl-sn-glycero-3-phosphorylcholine. The use of $\Delta^{9}$-octadecenoyl-CoA, $\Delta^{9,12}$ octadecadienoyl-CoA and $\Delta^{8,11,14}$-eicosatrienoyl-CoA for assaying acyl-CoA:1-acyl-sn-glycero-3-phosphorylcholine acyltransferase in the subcellular fraction yielded different specific activities as expected [44], but the relative specific activities were the same with all acyl-CoA derivatives. Thus, although acyl-CoA: 1-acyl-sn-glycero-3-phosphorylcholine acyltransferase activity may represent a series of enzymes, we have obtained no evidence to indicate different subcellular distributions when three very different acyl-CoAs were used as substrates. Similar results were observed with other acyltransferases (see Table 2).

Stoffel and Schiefer [42] have recently reported the presence of acyl-CoA: $s n$-glycero-3-phosphate acyltransferase, acyl-CoA:1-acyl-sn-glycero-3-phosphate acyltransferase and acyl-CoA:1-acyl-sn-gly- cero-3-phosphorylcholine acyltransferase in the outer membrane of mitochondria of rat liver. In the case of acyl-CoA :1-acyl-sn-glycero-3-phosphate acyltransferase, their data indicated that mitochondria contained the predominant activity; in the case of the other two acyltransferases, the mitochondria had specific activities greater than those of the homogenate but 3 to 4 times less than that of the microsomal fraction. Unfortunately, Stoffel and Schiefer did not include recovery of protein or enzymic activity in either the individual fractions or in the total homogenate. Such an omission renders it very difficult to make meaningful comparisons of our data with their data. In comparing our results from the microsomal fraction with those of Stoffel and Schiefer, it is readily apparent that our preparations had a much higher specific activity. For example, Stoffel and Schiefer reported a value of $102 \mathrm{nmole} / \mathrm{mg}$ protein/ $30 \mathrm{~min}$ with oleoyl-CoA:1-acyl-sn-glycero3-phosphorylcholine acyltransferase whereas our value represents $1300 \mathrm{nmoles} / \mathrm{mg}$ protein/30 min. In a similar sense, we may also directly compare specific activities for acyl-CoA:1-acyl-sn-glycero-3-phosphate acyltransferase. Stoffel and Schiefer reported specific activities (nmoles/mg/30 $\mathrm{min}$ ) of 2.4, 14.5 and 3.9 for total homogenate, whole mitochondria and microsomes respectively, which indicates a predominant localization of acyl-CoA:1-acyl-sn-glycero-3-phosphate acyltransferase in the mitochondria. On the other hand, our values expressed in terms of nmoles/ $\mathrm{mg} / 30 \mathrm{~min}$ for similar fractions were 156, 36 and 534 respectively (values are for oleoyl-CoA). Their lower values may reflect preparations of low specific activity or possibly an invalid assay with the $30 \mathrm{~min}$ incubation at $37^{\circ}$. We have no assurance from their reports that the reactions catalyzed by the various fractions proceeded at a constant rate during the time period studied. Since they assayed acyl-CoA: acyl-sn-glycero-3-phosphate acyltransferase by measuring the accumulation of radioactive acid in phosphatidates, it is possible that phosphatidate phosphohydrolyase destroyed some product as it was formed leading to an under-estimation of the acyltransferase activity. In particular, the low acyltransferase values reported for the total homogenate and microsomal fraction may be a result of phosphatidate phosphohydrolases described by Johnston et al. [45] and Smith et al. [46].

The subfractionation of microsomal membranes indicated in Table 3 allowed us to separate plasma membranes from microsomal membranes. The protein in the interface fraction showed a 10.7-fold purification of $5^{\prime}$-nucleotidase with relatively small amounts of glucose-6-phosphatase and acyltransferase activity (relative specific activities of 0.8 and 1.1 respectively). On the other hand the latter two activities were concentrated in the pellet, which represented about a 5 -fold purification of these two enzymes. In each step 
Table 3. Subfractionation of microsomal membranes

The specific activities and the relative specifio activities of three enzymes found in the microsomal subfractions at different stages of fractionation are given. The specific activity and relative specific activity are defined in Fig. 3. The values $0.25,0.70$, and 0.96 indicate the molarity of sucrose solutions which were always $1 \mathrm{mM}$ in EDTA. Subfractionation of the membranes was achieved by centrifugation of the microsomal particles through a boundary of 0.25 to $0.70 \mathrm{M}$ sucrose at $100000 \times g$ for $90 \mathrm{~min}$. The pellet was suspended in sucrose, and the loose layer was centrifuged through a boundary of 0.70 to $0.96 \mathrm{M}$ sucrose at $100000 \times g$ for $90 \mathrm{~min}$. The white protein fraction at the interface, enriched in plasma membranes [41], was collected

\begin{tabular}{|c|c|c|c|c|c|c|}
\hline \multirow[b]{2}{*}{ Fractions } & \multicolumn{3}{|c|}{ Specific activity } & \multicolumn{3}{|c|}{ Relative specific activity } \\
\hline & $\begin{array}{l}\text { Glucose-6- } \\
\text { phosphatase }\end{array}$ & $\begin{array}{l}\text { Linoleoyl- } \\
\text { CoA:1-acyl-8n- } \\
\text { glycero-3- } \\
\text { phosphoryl- } \\
\text { choline acyl- } \\
\text { transferase }\end{array}$ & $5^{\prime}$-Nucleotidase & $\begin{array}{l}\text { Glucose-6- } \\
\text { phosphatase }\end{array}$ & $\begin{array}{l}\text { Linoleoyl- } \\
\text { CoA:1-acyl-sn- } \\
\text { glycero-3- } \\
\text { phosphoryl- } \\
\text { choline acyl- } \\
\text { transferase }\end{array}$ & $5^{\prime}$-Nucleotidase \\
\hline $\begin{array}{l}\text { Homogenate } \\
\text { Microsomal fraction }\end{array}$ & $\begin{array}{l}26 \\
96\end{array}$ & $\begin{array}{l}11 \\
37\end{array}$ & $\begin{array}{r}9 \\
26\end{array}$ & $\begin{array}{l}1.0 \\
3.7\end{array}$ & $\begin{array}{l}1.0 \\
3.4\end{array}$ & $\begin{array}{l}1.0 \\
2.9\end{array}$ \\
\hline${\frac{0.25}{0.70} \underset{\downarrow}{\leftarrow} \rightarrow \text { pellet }}$ & 128 & 49 & 14 & 4.9 & 4.5 & 1.6 \\
\hline $\begin{array}{l}\text { loose layer } \\
\downarrow \downarrow \frac{0.70}{0.96}\end{array}$ & 61 & 23 & 65 & 2.3 & 2.1 & 7.2 \\
\hline Interface & 20 & 12 & 96 & 0.8 & 1.1 & 10.7 \\
\hline
\end{tabular}

of the preparation, the relative purification of glucose6-phosphatase and acyltransferase activities corresponded quite well; indicating again that the acyltransferases are localized in the endoplasmic reticulum. The report by Stein et al. [47] of similar specific activities for microsomal particles and plasma membranes was not confirmed by these experiments. However, Stein et al. did not give enough data for a direct comparison with our results. Moreover, they incubated free acids with $\mathrm{CoA}$ and ATP and gave no proof that their acyl transfer enzymes were saturated with thiol esters. With the two catalytic activities required in that system, the possibility arises that the acyltransferase reaction is the rate-limiting step in one subcellular fraction, and the ligase reaction limiting in the other. In this regard, Pande and Mead [48] indicated that acid:CoA ligase activity was higher in the cell membrane fraction than in the microsomal fraction. Further studies using 5 '-nucleotidase and glucose-6-phosphatase would help confirm this indication. Perhaps a low ligase activity in microsomes coupled with a high activity in plasma membranes would produce the nearly equal esterification of free acids by these two fractions observed by Stein et al. [47].

Our results with many substrate combinations suggest that generally the acyltransferases responsible for the transfer of fatty acids from acyl-CoA into monoacylglycerophospholipids are localized in the microsomal particles. There was no indication, that plasma membrane had appreciable amounts of acyltransferase activity. The similarity between the subcellular distribution of glucose-6-phosphatase and acyl-CoA:1-acyl-sn-glycero-3-phosphorylcholine acyltransferase suggests that the latter could be a very useful marker enzyme for microsomal particles in other cell-subfractionation studies. Acyltransferases, with their wide distribution in cells of different functions, may be more useful than glucose6-phosphatase which is absent in many tissues [40] and in our studies has not been detected in lung and heart of rats. However, it remains to be demonstrated that our findings with acyltransferases of rat liver are valid for other tissues.

In addition, the reports of phospholipase activities in many subcellular particles (e.g., mitochondria, lysosomes and microsomes) should be carefully checked with marker enzymes. Valid reaction rates and recovery of total activities are needed to prove whether these activities are really due to the particle considered or produced by contamination with other particles. In experiments with very long incubation times [13-16], small contaminations by active particles may produce considerable amounts of product not due to enzymes in the principal particles present.

The composition of phospholipids [49] and their fatty acid residues [50] in subcellular particles are known to be very similar. These results and the earlier observations about the de novo synthesis of lecithin suggest that in rat liver the phospholipids are synthesized at one place, the endoplasmic reticulum. The other subcellular membranes apparently gain their phospholipid composition by addition of preformed phospholipids [51] rather than by their own synthetic ability. 
This work was supported in part by a research grant from the United States Public Health Service (AM-05310) and by a fellowship from the Max-Planck-Gesellschaft. A preliminary report of this work was presented at the 42nd Fall Meeting of the American Oil Chemists' Society, New York, October 1968.

\section{REFERENCES}

1. European J. Biochem. 2 (1967) 127.

2. Gurr, M. I., Prottey, C., and Hawthorne, J. N., Biochim. Biophys. Acta, 106 (1965) 357.

3. Wilgram, G. F., and Kennedy, E. P., J. Biol. Chem. 238 (1963) 2615.

4. Bremer, J., and Greenberg, D. M., Biochim. Biophys. Acta, 37 (1960) 173.

5. Lands, W. E. M., Ann. Rev. Biochem. 34 (1965) 313.

6. Lands, W. E. M., J. Biol. Chem. 235 (1960) 2233.

7. Van Den Bosch, H., Van Golde. L. M. G., Eibl, H., and Van Deenen, L. L. M., Biochim. Biophys. Acta, 144 (1967) 613.

8. Stoffel, W., Schiefer, H. G., and Wolf, G. D., Z. Physiol. Chem. 347 (1966) 102.

9. Webster, G. R., Biochim. Biophys. Acta, 64 (1962) 573.

10. Lands, W. E. M., J. Amer. Oil Chemists' Soc. 42 (1965) 465.

11. Scherphof, G. L., and Van Deenen, L. L. M., Biochim. Biophys. Acta, 113 (1966) 417.

12. Turkki, P. R., and Glenn, J. L., Biochim. Biophys. Acta, $152(1968) 104$.

13. Scherphof, G. L., Waite, M., and Van Deenen, L. L. M., Biochim. Biophys. Acta, 125 (1966) 406.

14. Bjørnstad, P., Biochim. Biophys. Acta, 116 (1966) 500.

15. Waite, M., and Van Deenen, I. L. M., Biochim. Biophys. Acta, 137 (1967) 498.

16. Bjørnstad, P., J. Lipid Res. 7 (1966) 612.

17. Lands, W. E. M., J. Biol. Chem. 231 (1958) 883.

18. Robertson, A. F., and Lands, W. E. M., J. Lipid Res. 5 (1964) 88.

19. Waku, K., and Lands,W.E.M., J. Lipid Res. 9 (1968) 12.

20. Munder, P. G., Ferber, E., and Fischer, H., Z. Naturforsch. $20 \mathrm{~b}$ (1965) 1048.

21. Stein, Y., and Stein, O., Biochim. Biophys. Acta, 116 (1966) 95.

22. Reitz, R. C., Lands, W. E. M., Christie, W. W., and Holman, R. T., J. Biol. Chem. 243 (1968) 2241.

23. Seubert, W., Biochem. Prep. 7 (1960) 80.

24. Baer, E., and Kindler, A., Biochemistry, 1 (1962) 518.

25. Hill, E. E., Husbands, D. R., and Lands, W. E. M., J. Biol. Chem. 243 (1968) 4440.

26. Eibl, H., and Westphal, O., Liebigs Ann. Chem. 709 (1967) 244.
27. Warburg, O., and Christian, W., Biochem. Z. 310 (1942) 384.

28. Lowry, O. H., Rosebrough, N. J., Farr, A. L., and Randall, R. J., J. Biol. Chem. 193 (1951) 265.

29. Quagliariello, E., Landriscina, C., and Coratelli, P., Biochim. Biophys. Acta, 164 (1968) 12.

30. De Duve, C., Pressman, B. C., Gianetto, R., Wattiaux, R., and Appelmans, F., Biochem. J. 60 (1955) 604.

31. Cooperstein, S. J., Lazarow, A., and Kurfess, N. J., J. Biol. Chem. 186 (1950) 129.

32. Wattiaux, R., and De Duve, C., Biochem. J. 63 (1956) 606.

33. Hübscher, G., and West, G. R., Nature, 205 (1965) 799.

34. Eibl, H., and Lands, W. E. M., Anal. Biochem., in press.

35. Emmelot, P., Bos, C. J., Benedetti, E. L., and Rümke, Ph., Biochim. Biophys. Acta, 90 (1964) 126.

36. Snyder, F., Anal. Biochem. 9 (1964) 183.

37. Lands, W. E. M., and Hart, P., J. Biol. Chem. 240 (1965) 1905 .

38. Eibl, H., Reman, F. C., and Van Deenen, L. L. M., unpublished results.

39. Eibl, H., Demel, R. A., and Van Deenen, L. L. M., J. Coll. Intert. Science, 29 (1969) 381.

40. De Duve, C., J. Theoret. Biol. 6 (1964) 33.

41. Coleman, R., Michell, R. H., Finean, J. B., and Hawthome, J. N., Biochim. Biophys. Acta, 135 (1967) 573.

42. Stoffel, W., and Schiefer, H. G., Z. Physiol. Chem. 349 (1968) 1017.

43. Reitz, R. C., EI-Sheikh, M., Lands, W. E. M., Ismail, I. A., and Gunstone, G., Biochim. Biophys. Acta, 176 (1969) 480.

44. Hill, E. E., and Lands, W. E. M., Biochim. Biophys. Acta, 152 (1968) 645.

45. Johnston, J. M., Rao, G. A., Lowe, P. A., and Schwarz, B. E., Lipids, 3 (1966) 14.

46. Smith, M. E., Sedgwick, B., Brindly, D. N., and Hübscher, G., European J. Biochem. 3 (1967) 70.

47. Stein, Y., Widnell, C., and Stein, O., J. Cell Biol. 39 (1968) 185.

48. Pande, S. V., and Mead, J. F., J. Biol. Chem. 243 (1968) 352.

49. Getz, G. S., Bartley, W., Lurie, D., and Notton, B. M., Biochim. Biophys. Acta, 152 (1968) 325.

50. Fleischer, S., and Rouser, G., J. Amer. Oil Chemists' Soc. 42 (1965) 588.

51. Wirtz, K. W. A., and Zilversmit, D. B., J. Biol. Chem. 243 (1968) 3596.

H. Eibl, E. E. Hill, and W. E. M. Lands

Department of Biological Chemistry, University of Michigan Ann Arbor, Michigan 48104, U.S.A. 